\title{
The dissection of $R$ genes and locus Pc5.1 in Phytophthora capsici infection provides a novel view of disease resistance in peppers
}

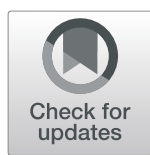

Jin-Song Dư, Lin-Feng Hang ${ }^{\dagger}$, Qian Hao, Hai-Tao Yang, Siyad Ali, Radwa Salah Ezaat Badawy, Xiao-Yu Xu, Hua-Qiang Tan, Li-Hong Su, Huan-Xiu Li, Kai-Xi Zou, Yu Li, Bo Sun, Li-Jin Lin and Yun-Song Lai*

\begin{abstract}
Background: Phytophthora capsici root rot (PRR) is a disastrous disease in peppers (Capsicum spp.) caused by soilborne oomycete with typical symptoms of necrosis and constriction at the basal stem and consequent plant wilting. Most studies on the QTL mapping of $P$. capsici resistance suggested a consensus broad-spectrum QTL on chromosome 5 named PC.5.1 regardless of $P$. capsici isolates and resistant resources. In addition, all these reports proposed NBS-ARC domain genes as candidate genes controlling resistance.

Results: We screened out 10 PRR-resistant resources from 160 Capsicum germplasm and inspected the response of locus PC.5.1 and NBS-ARC genes during P. capsici infection by comparing the root transcriptomes of resistant pepper 305R and susceptible pepper 3725. To dissect the structure of Pc.5.1, we anchored genetic markers onto pepper genomic sequence and made an extended Pc5.1 (Ext-Pc5.1) located at $8.35 \mathrm{Mb}-38.13 \mathrm{Mb}$ on chromosome 5 which covered all PC5.1 reported in publications. A total of 571 NBS-ARC genes were mined from the genome of pepper CM334 and 34 genes were significantly affected by P. capsici infection in either 305R or 372S. Only 5 inducible NBS-ARC genes had LRR domains and none of them was positioned at Ext-Pc5.1. Ext-Pc5.1 did show strong response to $P$. capsici infection and there were a total of 44 differentially expressed genes (DEGs), but no candidate genes proposed by previous publications was included. Snakin-1 (SN1), a well-known antimicrobial peptide gene located at PC5.1, was significantly decreased in 372S but not in 305R. Moreover, there was an impressive upregulation of sugar pathway genes in 305R, which was confirmed by metabolite analysis of roots. The biological processes of histone methylation, histone phosphorylation, DNA methylation, and nucleosome assembly were strongly activated in 305R but not in 372S, indicating an epigenetic-related defense mechanism.
\end{abstract}

Conclusions: Those NBS-ARC genes that were suggested to contribute to PC5.1 in previous publications did not show any significant response in $P$. capsici infection and there were no significant differences of these genes in transcription levels between 305R and 372S. Other pathogen defense-related genes like SN1 might account for $P C 5.1$. Our study also proposed the important role of sugar and epigenetic regulation in the defense against $P$. capsici.

Keywords: Root rot, Disease resistance, $R$ gene, NBS-ARC domain, RNA-seq

\footnotetext{
*Correspondence: laiys@sicau.edu.cn

${ }^{\dagger}$ Jin-Song Du and Lin-Feng Hang contributed equally to this work.

College of Horticulture, Sichuan Agricultural University, Chengdu 611130,

China
}

(c) The Author(s). 2021 Open Access This article is licensed under a Creative Commons Attribution 4.0 International License, which permits use, sharing, adaptation, distribution and reproduction in any medium or format, as long as you give appropriate credit to the original author(s) and the source, provide a link to the Creative Commons licence, and indicate if changes were made. The images or other third party material in this article are included in the article's Creative Commons licence, unless indicated otherwise in a credit line to the material. If material is not included in the article's Creative Commons licence and your intended use is not permitted by statutory regulation or exceeds the permitted use, you will need to obtain permission directly from the copyright holder. To view a copy of this licence, visit http://creativecommons.org/licenses/by/4.0/ The Creative Commons Public Domain Dedication waiver (http://creativecommons.org/publicdomain/zero/1.0/) applies to the data made available in this article, unless otherwise stated in a credit line to the data. 


\section{Background}

Oomycete Phytophthora capsici is a soilborn pathogen fungus that causes fruit rot, stem blight, foliar blight, and particularly root rot in peppers depending on the disease occurrence position [1]. P. capsici root rot (PRR) is a devastating pepper disease with typical symptoms of necrosis and constriction at the basal stem and consequent plant wilting. P. capsici basically spread via soil and splashing water in the form of microzoospores, and the disease PRR can break out very quickly in summer 1-2 days after rainfall due to field ponding. In protected cultivation, root rot occurs frequently 1-2 months after transplantation, especially in the case of continuous cropping. Resistance breeding is the first choice to prevent disease damage. A resistance genetic source PI201234 was first found in pepper [2]. The best known source is 'Criollo de Morelos-334' (CM334), which is also the sequencing material due to its perfect resistance [3]. It is still important to explore more genetic resources of $P$. capsici resistance.

Disease PRR was first reported in 1918 in the US, which was later found to be caused by $P$. capsica, a new fungus species [4]. Hence, phytopathologists and microbiologists have made great efforts to understand its pathogenic features [5]. P. capsici has even become a model pathogen in the study of plant-microbe interactions due to its wide range of hosts, including potato, tomato, cucurbits, beans, Arabidopsis and tobacco [6-8]. On the attack side, Phytophthora pathogens secrete and dispatch effectors such as RxLR into host cells, which paralyse the plant host immune system, including basal immune system named pattern-triggered immunity (PTI) [9], endoplasmic reticulum (ER) stress-mediated plant immunity [10], and the EDS-PAD4 immune signaling pathway [11]. In addition, pathogenic effectors can also disturb histone acetylation [12] and ethylene biosynthesis [13].

On the other side of host defense, plants develop PTI to detect nonspecific pathogen/microbe-associated molecular patterns (P/MAMPs), and effector-triggered immunity (ETI) which is resistance specific and accompanied by a hypersensitive response (HR) [14]. In the ETI system, NBS (nucleotide binding site)-ARC (apoptosis, $\mathrm{R}$ proteins, CED-4)-LRR (leucine rich repeat) proteins recognize pathogenic effectors and trigger downstream defense processes, including a rapid and strong oxidative burst, pathogenesis-related (PR) gene expression, and accumulation of antimicrobial compounds. NBS-ARC-LRR protein genes constitute the predominant majority of disease resistance genes $(R$ genes). Several doses of $R$ genes have been amplified in peppers by degenerate primers $[15,16]$. However, most $R$ genes are still unknown because higher plants typically have hundreds of $R$ genes. As demonstrated in potato
[17] and many other higher plants, pepper $R$ gene proteins should also optionally have conserved domains of toll/interleukin-1 receptor (TIR), coiled-coil (CC), and resistance to powdery mildew 8 (RPW8) in addition to NBS, ARC and LRR. Among these above domains, the NBS-ARC domain is the most conserved and is widely used to identify $R$ genes.

QTL mapping of pepper resistance to $P$. capsici was first reported in 1996 [18]. In this study, 13 QTLs were identified using the F2 mapping population of Perennial and YOLO Wonder, and one QTL linked to molecular marker TG483 on chromosome 5 had a major effect on resistance, which explained $41-55 \%$ of the total variance. Since then, many studies have confirmed these QTLs on chromosome 5 using different genetic resources (mostly CM334), mapping populations, and mapping strategies [19-23]. Based on the above studies, Mallard et al. (2013) constructed three consensus QTLs on chromosome 5 by using anchor markers and meta-analysis [24]. Meta-Pc5.1 and Meta-Pc5.3 were positioned close to teach other on the short arm of the chromosome and Meta-Pc5.2 was on the long arm. Recent QTL mapping work again confirmed the major QTL on the short arm of chromosome 5 [25-27]. Now, it is very clear that the major QTL Pc5.1 is a broad-spectrum QTL that controls resistance to all $P$. capsici. All the reports proposed $R$ genes at Pc5.1 as candidate genes. However, the detailed genetic mechanism remains unknown, and the function of these $R$ genes needs to be characterized. The pepper genome sequences of CM334 and Zunla were independently released in 2014 [28, 29], which enabled a thorough dissection of QTL structure.

In this study, we identified NBS-ARC candidate genes by mining the genomic sequence and profiled the responses of these genes in $P$. capsici infection. We also constructed an extended Pc5.1 (Ext-Pc5.1) to cover all reported QTLs from different QTL mapping works and profiled the responses of the genes on this locus in $P$. capsici infection. The comparison of root metabolites and root transcriptome between resistant and sensitive peppers in $P$. capsici infection renewed our understanding about the roles of $R$ genes and QTL Pc5.1and provide new insights in $P$. capsica-resistance.

\section{Results}

\section{Resistance assessment of Capsicum germplasm}

Pepper seedlings with 6 leaves were inoculated with $P$. capsici by injecting zoospores into the soil around the basal stem (Fig. 1). A total of 160 germplasm materials were subjected to the resistance assessment. As a result, we identified 10 materials of high resistance (HR), 7 materials of resistance (R), 31 materials of moderate resistance (MR), and 112 materials of nonresistance (NR) (Additional file 1: Table S1). The HR pepper germplasm 


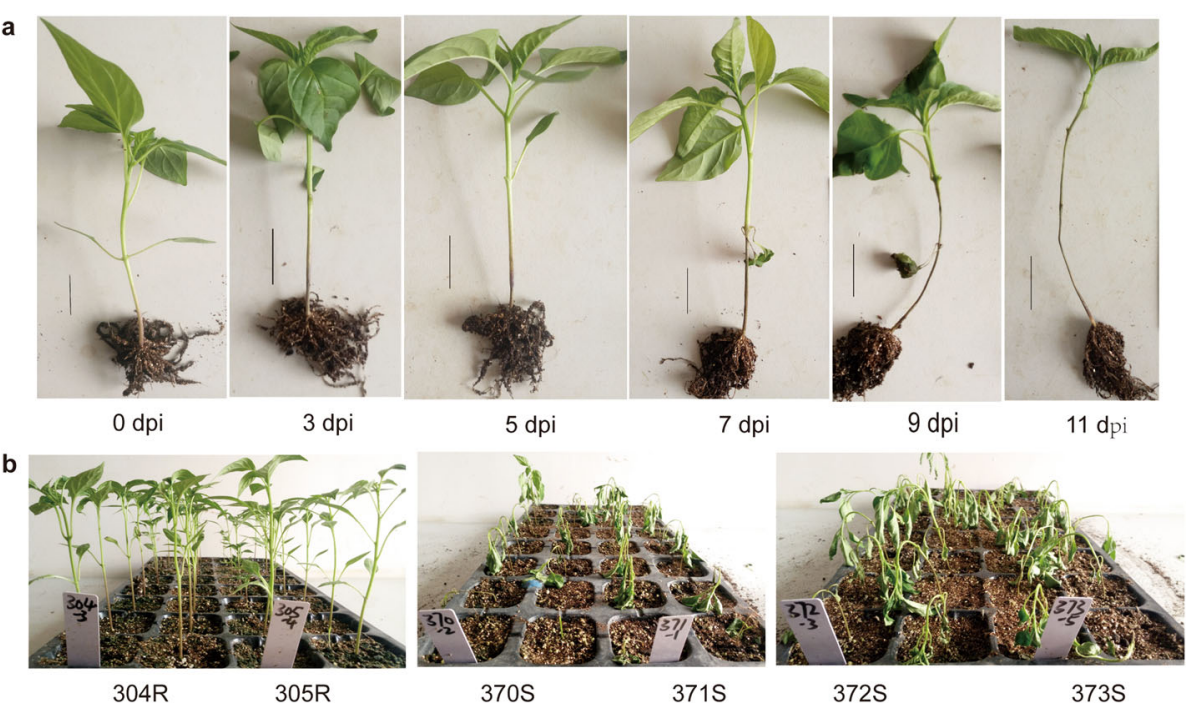

Fig. 1 Symptom of $P$. capsici root rot (PRR). a Dynamic symptom after root inoculation. $\mathbf{b}$ Comparison of $P$. capsici resistance between resistant and susceptible pepper materials at 7 days post inoculation (dpi)

showed comparable resistance to CM334. The ten HR germplasms included 2 bell peppers, 5 cayenne peppers, 1 cluster pepper, 1 linear pepper (var. annuum L. dactylus $\mathrm{M}$ ), and 1 upward pepper (var. conoide (Mill.) Isish). We selected four accession (304R, linear pepper; 305R, upward pepper; $370 \mathrm{~S}$, cone pepper; 372S, cayenne pepper) to be used in the following experiments that represented different pepper types.

\section{Primary metabolites in infected roots}

Ethanol extract from inoculated roots was subjected to GC-MS, which revealed dynamic changes in primary metabolites responding to $P$. capsici infection (Fig. 2). All inner standards were salinized, which indicates total and successful derivatization. Resistant accessions 304R and 305R show different alteration profiles to $370 \mathrm{~S}$ and $372 \mathrm{~S}$ in respect of sugar contents. There was a sharp increase of sucrose at 3 days post inoculation ( $3 \mathrm{dpi}$ ) in resistant peppers but decrease in susceptible peppers. Similarly, tagatose, fructose and mannose were strongly increased in 304R and 305R but decrease in susceptible peppers particularly 370S. In addition, propanetricarboxylic acid and butanedioic acid were reduced quickly after $P$. capsici inoculation in 370 S and 372 S but not in resistant materials. No additional consensus differences between resistant peppers and susceptible peppers were observed for the remaining compounds. The robust response of sugar contents may enhance the resistance against $P$. capsici.

\section{Transcriptome of infected roots}

We performed RNA-seq using roots of 305R and 372S to profile the dynamic response of the major QTL and
NBS-LRR genes that may contribute to resistance against P. capsici (Additional file 2: Table S2). The transcriptome at $3 \mathrm{dpi}$ was compared with that at $0 \mathrm{dpi}$ to identify differentially expressed genes (DEGs) caused by P. capsici. As a result, a total of 3073 and 1743 DEGs were identified in 305R and 372S, respectively (Fig. 3a; Additional file 3: Table S3; Additional file 4: Table S4). For both $372 \mathrm{~S}$ and $305 \mathrm{R}$, there were more upregulated DEGs than downregulated DEGs. There were many more DEGs in 305R than in 372S, indicating a strong defense response in 305R. This finding is interesting when considering that a visible symptom was noted for 372 S, but no change in appearance was noted for 305R.

In KEGG enrichment analysis, the largest differences were noted in the pathways of valine, leucine and isoleucine degradation (ko00280, downregulated) and starch and sucrose metabolism (ko00500, upregulated) in 305R as well as carotenoid biosynthesis (ko00906, upregulated) and plant hormone signal transduction (04075) in $372 S$ (Table 1; Additional file 8: Figure S1). Pathogen infection repressed the expression of ethylene signal transduction genes in $372 \mathrm{~S}$ and disturbed other phytohormone signal pathways, including auxin, cytokinine, gibberellin, abscisic acid, brassinosteroid, jasmonic acid, and salicylic acid. Significant enrichments of both phenylpropanoid biosynthesis and glutathione metabolism were found in 305R and 372S.

In the GO enrichment analysis, only 3 significant enrichments were shared by $305 \mathrm{R}$ and $372 \mathrm{~S}$, indicating very different responses of the transcriptome to $P$. capsici (Table 2; Additional file 9: Figure S2). Notably, 20 DEGs in 305R were enriched under the GO term "response to endoplasmic reticulum (ER) stress", whereas 


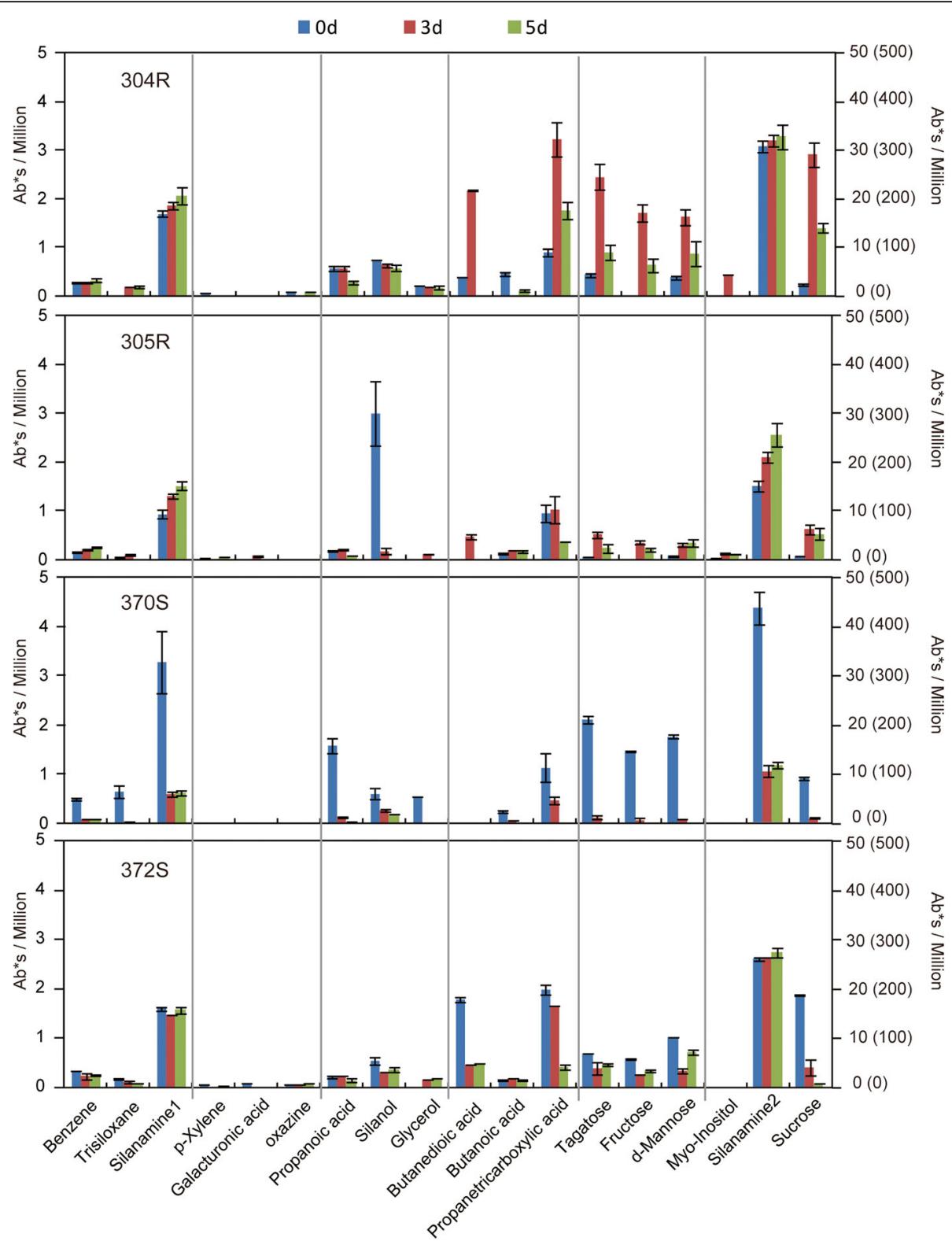

Fig. 2 Dynamic profiles of partial metabolites detected in roots were compared between resistant and susceptible peppers. The compound of each metabolite is simply measured by peak area. Sucrose matches the value of the right y-axis outside the parentheses. Silanamine2 matches the value of the right $y$-axis inside the parentheses. The remaining compounds match the left $y$-axis. The column bar indicates SE

that number was 7 in 372 , indicating a differential response in ER stress-mediated plant immunity. As a successful defense, 305R also shows an impressive response inside nuclear processes including nucleosome assembly and DNA replication initiation, epigenetic processes including, chromatin silencing by small RNA, methylationdependent chromatin silencing, histone methylation and phosphorylation, and DNA methylation. A total of 117 genes were assigned with epigenetic-related biological processes among which 42 genes were significantly affected by $P$. capsici in 305R while that number was 4 in 372S (Additional file 5: Table S5). We found many interesting DEGs responding to P. capsici in 305R, e.g., Histone, ATP-dependent DNA helicase, Chromatin structure-remodeling complex protein, NBS-LRR and Pentatricopeptide repeat-containing protein that may generate phasiRNAs in dicots [30].

Based on the results above of the enrichment analysis, we further compared the expression of DEGs under several interesting KEGG pathways or GO terms (Fig. 3be). DEGs involved in "endoplasmic reticulum stress" and epigenetic modification were notably upregulated in 305R. Interestingly, under the GO term "fungus response", 12 DEGs out of 19 DEGs were downregulated 

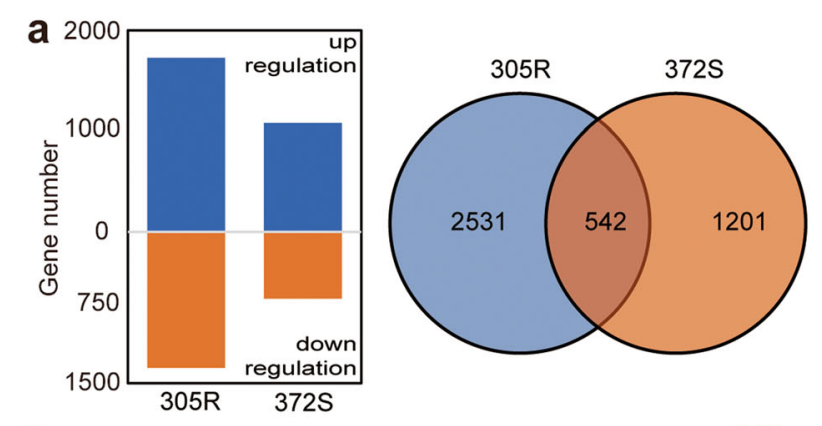

C

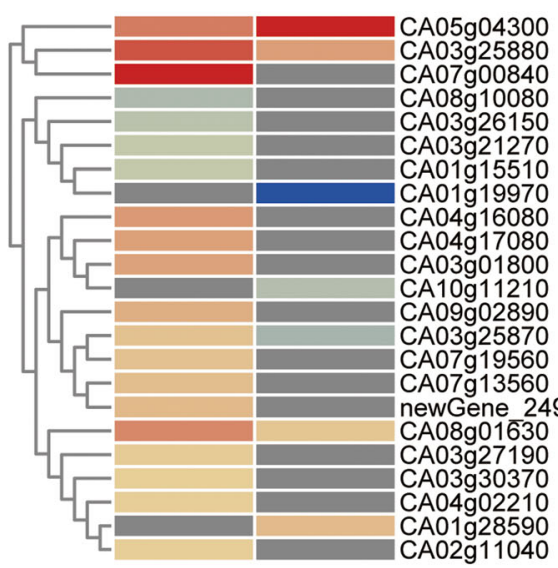

d

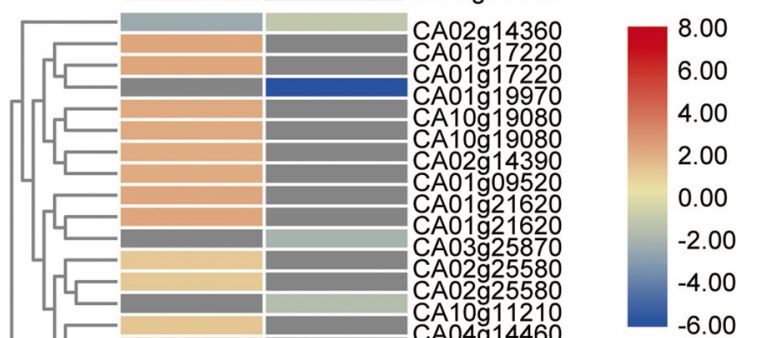

b
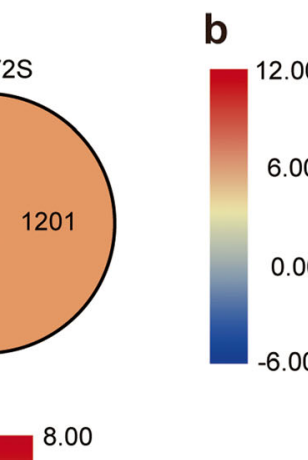

6.00

4.00

2.00

0.00

$-2.00$

$-4.00$

$-6.00$

$-6.00$

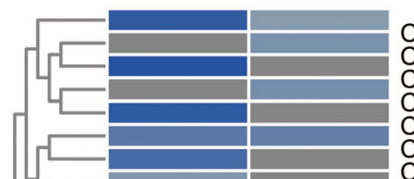

CA07g00420

CA03923090

CAO19050

CA11g08840

CA03g00430

CA08g01100

CA07g16920

newGene 24545

CA07g08230

CA02g13000

CA11906380

CA05908540

CA10g03710

CA09g14590

CA02g24100

CA12g00580

CA12g00580

CA06g 16700

CA06g 16700

CA01917380

CA02g17350

CA01900580

CA03g28140

CA04g04420

CA08g08110

CA02g17760

CA11g14410

CA06g17350

CA01g22110

CA09g14640

CA12g03490

CA09g14130

CA03g23130

CA10g07080

CA03g07630

CA01g02840

CA04g15910

CA12g10900

CA03g02150

CA02 25020

CA02g25020

CA3g22910

newGene 25114

CA01g15640

CA01g15640

CA07g17910

CA04g05210

CA01915630

newGene 14104

CA03g14620

CAO3g14300

CAO3g18300

CA0890820

CA05g 16100

CA11g02740

CA10g12470

CA10g10690

CA04914450

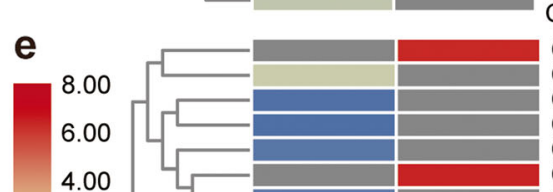

CA08G09970

CA02G17450

CA02G17450

CA10G06360

CA07G15380

CA09G03050

CA03G26150

newGene 15140

CA02G18160

CA01G15510

CA10G16870

CA03G28060

CA08G12430

CA03G17210

CA03G17210

CA04G13750

CA07G04330

CA08G10010

CA05G01410

CA08G10000

CA02G23660

CA04G15610

CA11G03520

CA11G04410

CA10G11210

CA03G27190

Fig. 3 (See legend on next page.) 
(See figure on previous page.)

Fig. 3 Differential response of gene expression to P. capsici infection at 3 days post inoculation (dpi). a Change trend (left) and Venn diagram (right) of DEGs in pepper 305R and 372S. Genes involved in starch and sucrose metabolism (ko00500, b) as well as biological processes related to

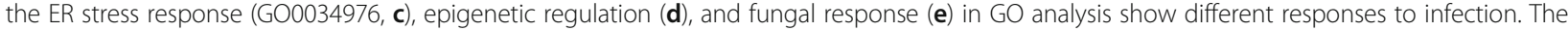
color of the heatmap indicates the value of $\log _{2}$ (FPKM-3 dpi/FPKM-0 dpi)

in 305R, whereas 3 out of 8 were downregulated in 372S. As expected, the phenylpropanoid pathway, which produces secondary metabolites such as flavonoids and lignins, was upregulated in 305R (Additional file 10: Figure S3). In the sugar pathway, 33 DEGs out of 42 DEGs in $305 \mathrm{R}$ were upregulated, whereas only 14 out of 24 were upregulated in $372 \mathrm{~S}$. Clearly, sugar pathway in $305 \mathrm{R}$ was stimulated by the fungus infection. In a detail, there was a clear upregulation of genes involved in the conversion from glucose to sucrose and fructose in 305R (Fig. 4) but not in 372S (Additional file 11: Figure S4). This corresponds well with increased sugar compounds in metabolite analysis.

\section{Identification of NBS-ARC genes and their responses to $P$. capsici}

A total of 823 candidate NBS-ARC domain proteins were identified by searching the HMM file (PF00931) against the whole-genome peptide sequences. The number increased to 1226 with an $E$ value $<0.01$ when using the pepper-specific HMM file. Finally, we identified 571 NBS-ARC domain proteins after removing short amino acid sequences. Complete assessment using the CDSearch Tool indicated 390 proteins with a complete NBS-ARC domain. As expected, all the NB-ARC domain genes were clustered among the pepper genomes, particularly at chromosome arms (Additional file 12: Figure $\mathrm{S} 5)$. These proteins were grouped according to the repetition and position of NBS-ARC, TIR, CC, LRR, RPW8 as well as coiled coil domain of the potato virus $\mathrm{X}$ resistance ( $\mathrm{RX}-\mathrm{CC}$, abbreviated as $\mathrm{Cx}$ in this study) (Table 3; Additional file 6: Table S6; Additional file 7: Table S7). The conserved domains and motifs as well as the gene structure of all the NBS-ARC genes were analyzed (Additional file 13: Figure S6). In the pepper genome, there are only 3 TIR-NBS genes, which is notably fewer than in other higher plants. In addition, the three TIR-NBS proteins did not have other representative domains. Among the non-TIR-NBS genes, 204 proteins have LRR domains that may play a role in the recognition of pathogenic effectors. Large variance is noted in the number of LRR domains, which implies coevolution with diseases. For example, one CxNL-type protein (CA01g31440) had as many as 12 LRR domains. CC domains appear frequently in pepper NBS-ARC proteins. There were 118 proteins with CC domains and another 193 proteins that did not have CC domains but had Cx domains. Only 23 proteins had RPW8 domains.

The polygenetic tree indicates that NBS-ARC domain genes in the same cluster on chromosomes have high identity, e.g., genes on chromosomes 6 and 11 (Fig. 5a). Interestingly, genes with long branches, e.g., CA04g19370, CA04g09960, CA00g93130, and CA02g25810, might experience the acquisition of CC, Cx, LRR, or RPW8 domains (Fig. 5b). In total, 32 NBS-ARC genes exhibit a significant response to $P$. capsici infection, which were mainly clustered on chromosomes 3, 5, and 7 (Fig. 6a). Among them, only 2 had a CC domain, 1 had an RPCW8 domain, and 5 had an LRR domain (Fig. 6b). The 5 NBLRR genes are probably $P$. capsici isolate-specific.

Table 1 Pathways showing significant enrichment in KEGG analysis

\begin{tabular}{|c|c|c|c|c|c|}
\hline \multirow[t]{2}{*}{ Pathway } & \multirow[t]{2}{*}{ KO ID } & \multirow[t]{2}{*}{$\mathrm{EF}^{\mathrm{a}}$} & \multirow{2}{*}{$\begin{array}{l}\text { Q- } \\
\text { value }\end{array}$} & \multicolumn{2}{|c|}{ Number of DEGs } \\
\hline & & & & $305 R$ & $372 S$ \\
\hline \multicolumn{6}{|l|}{ Root transcriptome of 305R } \\
\hline Phenylpropanoid biosynthesis & ko00940 & 1.815 & 0.034 & 35 & 25 \\
\hline Glutathione metabolism & ko00480 & 2.019 & 0.105 & 22 & 19 \\
\hline Valine, leucine and isoleucine degradation & ko00280 & 2.225 & 0.178 & 16 & - \\
\hline Starch and sucrose metabolism & ko00500 & 1.567 & 0.214 & 42 & 24 \\
\hline \multicolumn{6}{|l|}{ Root transcriptome of 3725} \\
\hline Glutathione metabolism & ko00480 & 3.209 & 0.000 & 22 & 19 \\
\hline Carotenoid biosynthesis & ko00906 & 4.406 & 0.001 & - & 12 \\
\hline Phenylpropanoid biosynthesis & ko00940 & 2.386 & 0.004 & 35 & 25 \\
\hline Plant hormone signal transduction & ko04075 & 2.045 & 0.009 & - & 31 \\
\hline
\end{tabular}


Table 2 Significant enrichment of biological processes in GO enrichment analysis

\begin{tabular}{|c|c|c|c|c|c|}
\hline \multirow[t]{2}{*}{ GO_ID } & \multirow[t]{2}{*}{ GO_Term } & \multirow{2}{*}{$\begin{array}{l}\text { Total } \\
\text { gene } \\
\text { number }\end{array}$} & \multirow{2}{*}{$\begin{array}{l}\text { Expected } \\
\text { DEG } \\
\text { number }\end{array}$} & \multicolumn{2}{|c|}{ DEG number } \\
\hline & & & & $305 R$ & $372 S$ \\
\hline \multicolumn{6}{|c|}{ Root transcriptome of 305R } \\
\hline GO:0008283 & Cell proliferation & 78 & 9.42 & 29 & 2 \\
\hline GO:0042542 & Response to hydrogen peroxide & 82 & 9.91 & 19 & 6 \\
\hline GO:0051567 & Histone H3-K9 methylation & 48 & 5.8 & 16 & 1 \\
\hline GO:0019684 & Photosynthesis, light reaction & 269 & 32.5 & 9 & 2 \\
\hline GO:0006334 & Nucleosome assembly & 43 & 5.2 & 20 & 2 \\
\hline GO:0016572 & Histone phosphorylation & 17 & 2.05 & 8 & 0 \\
\hline GO:0006270 & DNA replication initiation & 29 & 3.5 & 13 & 1 \\
\hline GO:0043086 & Negative regulation of catalytic activity & 104 & 12.57 & 20 & 22 \\
\hline GO:0006306 & DNA methylation & 60 & 7.25 & 17 & 2 \\
\hline GO:0034976 & Response to endoplasmic reticulum stress & 81 & 9.79 & 20 & 7 \\
\hline GO:0006346 & Methylation-dependent chromatin silencing & 23 & 2.78 & 6 & 1 \\
\hline GO:0009644 & Response to high light intensity & 53 & 6.4 & 18 & 6 \\
\hline GO:0022900 & Electron transport chain & 383 & 46.27 & 7 & 1 \\
\hline GO:0042777 & Plasma membrane ATP synthesis coupled proton transport & 44 & 5.32 & 0 & 0 \\
\hline GO:0009664 & Plant-type cell wall organization & 96 & 11.6 & 18 & 6 \\
\hline GO:0031048 & Chromatin silencing by small RNA & 16 & 1.93 & 5 & 0 \\
\hline GO:0009408 & Response to heat & 83 & 10.03 & 24 & 0 \\
\hline GO:0045893 & Positive regulation of transcription, DNA-templated & 107 & 12.93 & 15 & 5 \\
\hline GO:0043687 & Posttranslational protein modification & 28 & 3.38 & 2 & 1 \\
\hline \multicolumn{6}{|c|}{ Root transcriptome of 3725} \\
\hline GO:0043086 & Negative regulation of catalytic activity & 104 & 6.36 & 20 & 22 \\
\hline GO:0016099 & Monoterpenoid biosynthetic process & 11 & 0.67 & 0 & 1 \\
\hline GO:0042777 & Plasma membrane ATP synthesis coupled proton transport & 44 & 2.69 & 0 & 0 \\
\hline GO:0009411 & Response to UV & 63 & 3.85 & 10 & 4 \\
\hline GO:0055114 & Oxidation-reduction process & 1865 & 114.1 & 206 & 146 \\
\hline GO:0006355 & Regulation of transcription, DNA-templated & 647 & 39.58 & 95 & 55 \\
\hline GO:0010035 & Response to inorganic substance & 338 & 20.68 & 59 & 41 \\
\hline GO:0042542 & Response to hydrogen peroxide & 82 & 5.02 & 19 & 12 \\
\hline GO:0009825 & Multidimensional cell growth & 40 & 2.45 & 10 & 2 \\
\hline GO:0009908 & Flower development & 201 & 12.3 & 27 & 7 \\
\hline GO:0043687 & Posttranslational protein modification & 28 & 1.71 & 2 & 1 \\
\hline
\end{tabular}

All the biological processes had a $k s$ value $<0.001$

\section{Response of QTL PC5.1 to P. capsici}

QTL Pc5.1 is known a major and broad spectrum QTL [24]. We converted the genetic positions of molecular markers into physical positions in the CM334 genome by BLAST primer sequences or marker sequences against genome sequences (Fig. 7a). We coordinated the Meta-Pc5.1 locus (between markers C2 At1g33970 and C2_At3g51010) and the adjacent Meta-Pc5.3 locus (between markers TG483 and TG437). This chromosome segment positioned 8.35 $\mathrm{Mb}-38.13 \mathrm{Mb}$ on chromosome 5 (between markers
T1261 and C2_At2g01770) is taken as an extended Pc5.1 (Ext-Pc5.1) in this study.

A total of 44 DEGs were identified at Ext-Pc5.1 among which 34 DEGs were identified in 305R and 18 in 372S, indicating a stronger response in 305R than in 372S. In a detail, there were 11 DEGs at Meta-Pc5.1, 10 DEGs at Meta-Pc5.3 and 23 DEGs at the surrounding and conjunction regions. At Ext-Pc5.1, there were a total of 14 NBS-ARC genes but only one (CA05g04300) of them responded to $P$. capsici, which was induced in both 350R and 372S. Moreover, this $R$ gene positioned at Meta- 


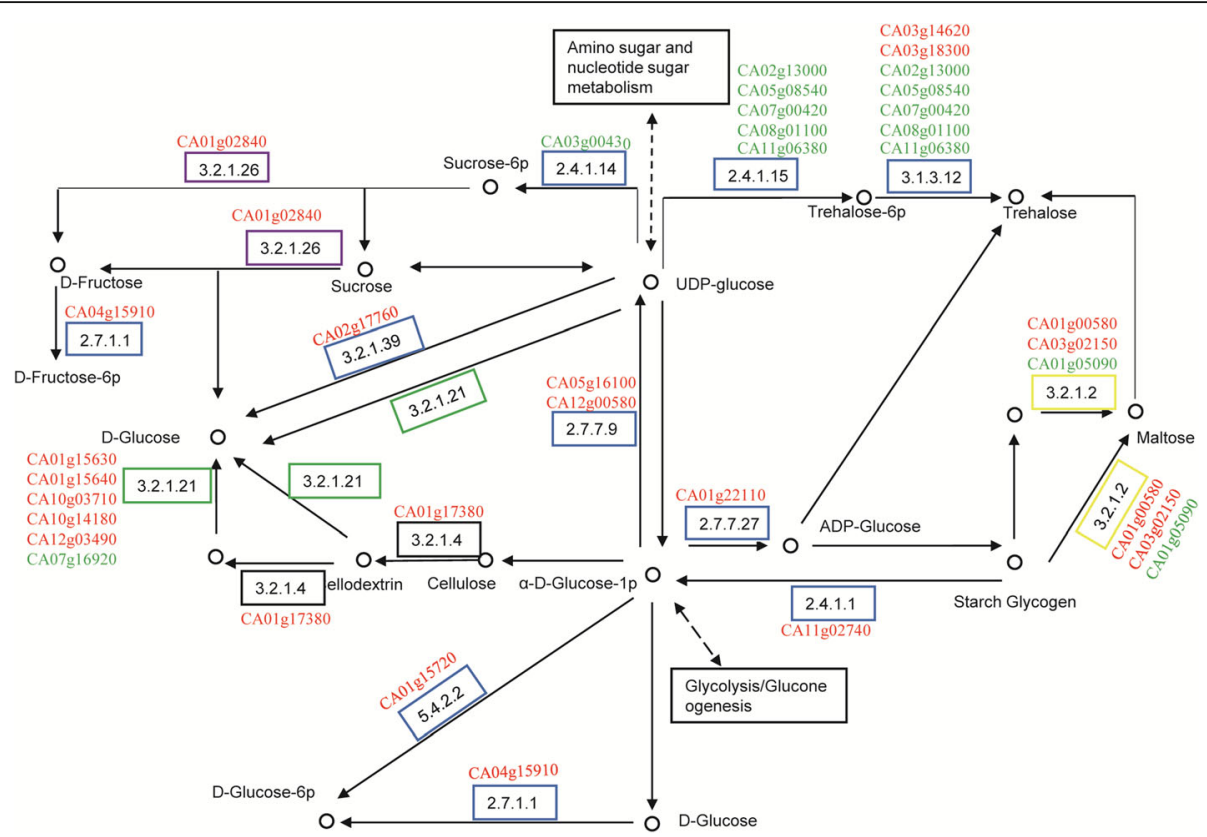

Fig. 4 The dynamic change of sugar pathway genes after P. capsici infection in 305R. The pathway map was made based on map 00500 (Starch and sucrose metabolism) from KEGG PATHWAY Database. Upregulated genes were labeled in red color while downregulated genes were labeled in green color

Pc5.3 and it is N-type. All the candidate genes including $R$ genes and other genes at Pc5.1 proposed in literatures did not show any significant response to $P$. capsici infection (see discussion) [25-27]. And there was no significant difference of these candidate genes in transcription level between 305R and 372S (data not shown). At Meta-Pc5.1, we found 3 DEGs showed different dynamic profile in the $P$. capsica-infection including snakin-1 (SN1), RING finger protein, and a transcription cofactor. Basically, their expression level was increased in 305R and decreased in $372 \mathrm{~S}$ after inoculation (Fig. 7b). Snakin-1 (SN1) is a well-known pathogen defense-related gene, which is characterized by its in vitro activity and targeted pathogens in wide-spectrum [31]. No SNP at coding regions was detected by comparing SN1 transcripts of $372 \mathrm{~S}$ and $305 \mathrm{R}$ (data not shown).

\section{Discussion}

Transcriptome comparison between resistant material and susceptible material enables us to discriminate the gene response, which should account for the difference in resistance. A recent study of the CM334 root transcriptome proposed that the upregulation of the phenylpropanoid biosynthesis pathway may play a role in resistance ( $\mathrm{Li}, 2020)$. We also observed the difference in the response of phenylpropanoid biosynthesis pathway between 305R and 372S (Additional file 9: Fig. S3). This differential response is not $P$. capsica-specific and it looks like a common phenomenon in plant resistance against diseases [32, 33]. Indeed, many other clear differences exist between $305 \mathrm{R}$ and $372 \mathrm{~S}$ in addition to the phenylpropanoid pathway. Valine, leucine and isoleucine are branched-chain amino acids (BCAAs) and play roles in plant growth, development, defense, and flavor [34]. The degradation pathway of BCAAs mainly occurs in mitochondria, and its downregulation may help maintain increased BCAA levels and enhance defense. Compared with 372 S, which shows a major response in the process of metabolism and oxidation, the dynamic change in the $305 \mathrm{R}$ transcriptome is enriched in nucleic processes, such as cell proliferation, DNA replication, nucleosome assembly and transcription regulation, which provides an interesting view about pathogen resistance. We also observed a strong response of epigenetic modification about DNA, histone, and chromatin in 305R but not in 372S. Many reports support the participation of epigenetic mechanisms in plant tolerance against biotic stress $[35,36]$. NBS-LRR and pentatricopeptide repeat-containing protein were enriched in processes of DNA methylation and histone methylation, which may generate phased secondary small interfering RNAs (phasiRNAs). The interaction of $R$ gene and miRNA-phasiRNA cascade contributes to the delicate control of $R$ gene-mediated disease resistance [37]. It is very necessary to profile the dynamic epigenetic change of DNA methylation, histone modification, chromatin remodeling, and small RNA in $P$. capsica-infection in the future. 
Table 3 A summary of NBS-ARC classification in peppers

\begin{tabular}{|c|c|c|c|}
\hline Group & Num.C ${ }^{a}$ & Num.IC ${ }^{b}$ & Sum \\
\hline $\mathrm{N}$-type & 90 & 84 & 174 \\
\hline NL-type & 44 & 36 & 80 \\
\hline \multicolumn{4}{|l|}{ CN-type } \\
\hline $\mathrm{CN}$ & 42 & 15 & 57 \\
\hline NC & 3 & 0 & 3 \\
\hline CNC & 1 & 0 & 1 \\
\hline $\mathrm{CxN}$ & 83 & 33 & 116 \\
\hline CxNCXN & 2 & 0 & 2 \\
\hline $\mathrm{NCxN}$ & 1 & 0 & 1 \\
\hline \multicolumn{4}{|l|}{ CNL-type } \\
\hline $\mathrm{CNL}$ & 38 & 1 & 39 \\
\hline NLC & 0 & 2 & 2 \\
\hline $\mathrm{NLCL}$ & 2 & 1 & 3 \\
\hline CxNL & 63 & 3 & 66 \\
\hline \multicolumn{4}{|l|}{ TN-type } \\
\hline $\mathrm{TN}$ & 1 & 1 & 2 \\
\hline TNT & 1 & 0 & 1 \\
\hline NT & 1 & 0 & 1 \\
\hline \multicolumn{4}{|l|}{ PN-type } \\
\hline PNL & 2 & 0 & 2 \\
\hline PCN & 3 & 2 & 5 \\
\hline PCNL & 8 & 0 & 8 \\
\hline PCXN & 1 & 2 & 3 \\
\hline PCXNL & 4 & 0 & 4 \\
\hline PCXPN & 0 & 1 & 1 \\
\hline Total & 390 & 180 & 570 \\
\hline
\end{tabular}

${ }^{a}$ num. C, Number of proteins with a complete NBS-ARC domain; ${ }^{b}$ num. IC, number of proteins with incomplete NBS-ARC domain

Notably, sugars including sucrose, tagatose, fructose and mannose were upregulated by pathogen infection in $305 \mathrm{R}$ but not in $372 \mathrm{~S}$, which was due to the differential response of sugar pathway-related genes in transcriptome. Sugars play roles as energy, carbon sources, and signaling molecules in plant-pathogen interactions [38, 39]. Some sugar pathway genes function as PR proteins, such as cell wall invertases (CWIs), which convert sucrose into glucose and fructose [40]. Many reports show the positive correlation of sugar accumulation with plant resistance against pathogenic microorganisms. For example, pretreatment with sucrose enhances resistance, and accordingly, rice plants overexpressing exotic PR genes accumulate more sucrose in leaves [41]. Apple adopts sorbitol to modulate resistance against fungal disease via NLR genes, and silencing synthesis results in a decrease in resistance [42]. The differential response of sugar accumulation and pathway genes was also observed in soybean infections when comparing resistant and susceptible materials [33]. Here, it is the first-time that sugars were reported to associate with $P$. capsica-resistance. Rapid upregulation of sugar after infection may be involved in lignification of the root cell wall or activate the downstream defense reaction as a part of plant immunity.

We identified a total of 571 NBS-ARC domain genes, 390 of which had a complete NBS-ARC domain. Before our study, only dozens of NBS-ARC genes were identified by degenerate PCR amplification [15, 16]. This is due to either the limitation of degenerate PCR or the absence of genomic sequences at that time. Although the NBS-ARC domain is conserved, sequence variance due to rapid evolution of the gene family is noted; therefore, a large portion of genes cannot be detected by degenerate PCR method. Pepper has an impressively large number of NBS-ARC genes when compared with other reports using similar mining approaches [43]. LRR is the most variable domain of NBS-ARC protein and is critical for recognition specificity in ETI defense reaction [44]. There was a total of 204 NBS-ARC genes possess LRR domains (NB-LRR), however, only 5 of them show significant response. These five NB-LRR genes might be specific to $P$. capsici isolate used in this study. Moreover, there are many more $P$. capsici inducible NBS-ARC genes in 305R than in 372S, which might mean an effective ETI defense reaction in 305R.

Unexpected novel QTLs were occasionally reported, e.g., on chromosome 10, when using a novel isolate of $P$. capsici $[26,45]$. Nevertheless, many more studies from the 1990s suggest a wide spectrum QTL on chromosome 5 regardless of resistance resources and QTL mapping strategies [18-23]. Mallard et al. (2013) performed a meta-analysis, compiled QTL mapping work published before, and finally determined three consensus QTLs on chromosome 5 among which Meta-Pc5.1 (positioned 19.48-29.03 Mb) and Meta-Pc5.3 (positioned 9.30$13.83 \mathrm{Mb}$ ) are close to each other on the short arm [24]. Recent studies confirmed again this conclusion. A single dominant gene, CaPhyto, was positioned at 30.98-32.43 $\mathrm{Mb}$ (originally $29.10-30.18 \mathrm{Mb}$ in the Zunla-1 genome) [25]. With the combination of biparental QTL mapping and GWAS, the wide spectrum QTL Pc5.1 (originally QTL5.2) against $3 \mathrm{P}$. capsici isolates was positioned at $27.3 \mathrm{Mb}$ [27]. Another two isolate-specific QTLs were identified near a region of $18.7-19.5 \mathrm{Mb}$ (Pc5.1 originally QT5.1) and 34.6-37 Mb. Most recently, Pc.5.1 at 27.16 $\mathrm{Mb}$ of chromosome 5 was detected again in the resistance to 4 isolates [26]. Taking into consideration these above QTL positions, we dissected the response of ExtPc5.1 with a region $8.35-38.13 \mathrm{Mb}$.

Despite the effort in genetic analysis, very little is known about the detailed genetic mechanism. In the resistant resource PI201234, two genes, CA05g06820 


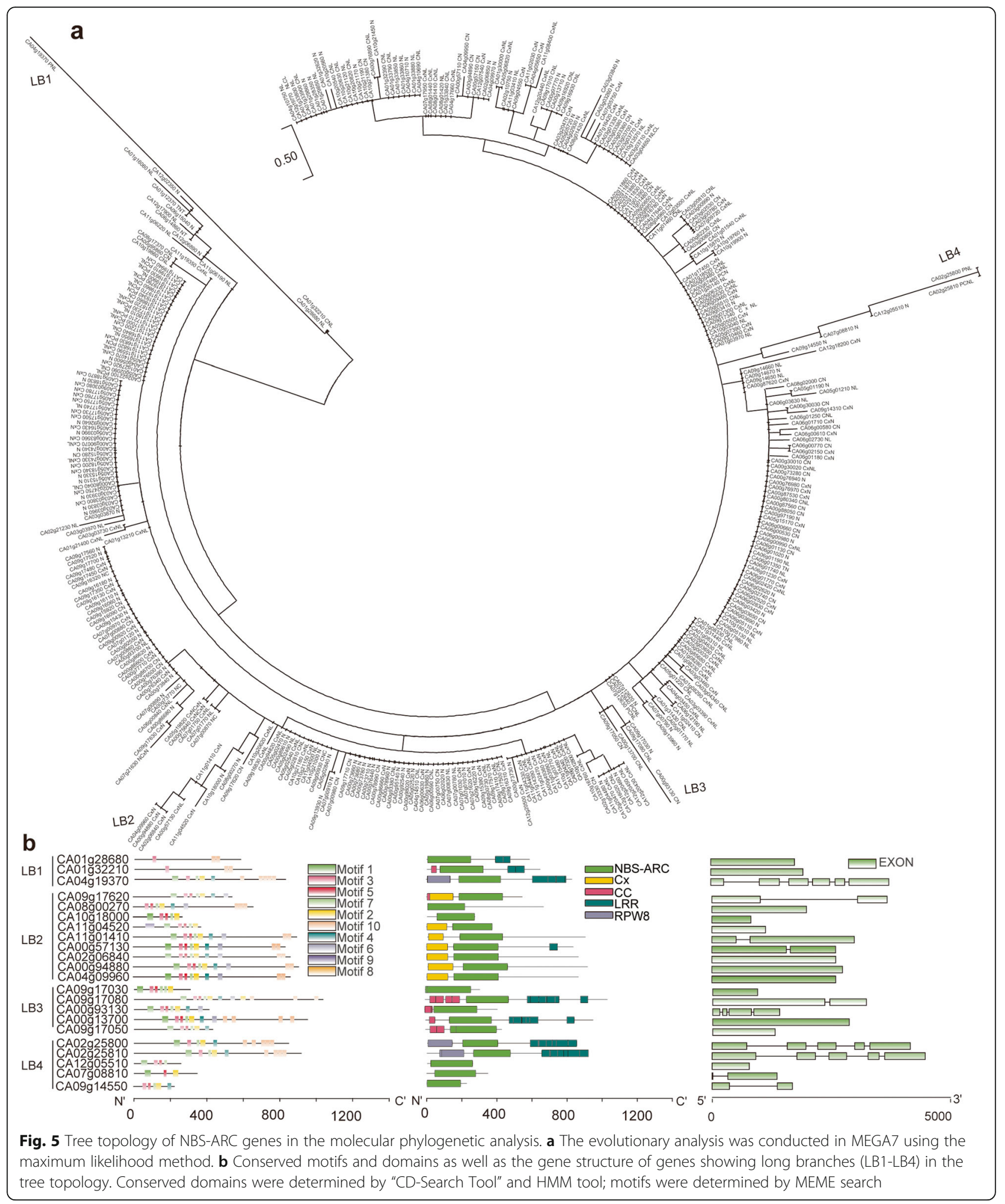

(RPP13-like, Capana05g000769 in the Zunla-1 genome) and CA05g06770 (serine/threonine-protein kinase BRI1like2, Capana05g000764 in the Zunla-1 genome), of Pc5.1 were proposed to control resistance [25]. At Pc5.1 of CM334, 2 RPP13-like genes, 3 RLK genes, and a systemic acquired resistance (SAR)-related gene are suggested candidate genes participating in resistance regulation [27]. Chunthawodtiporn et al. (2019) again 


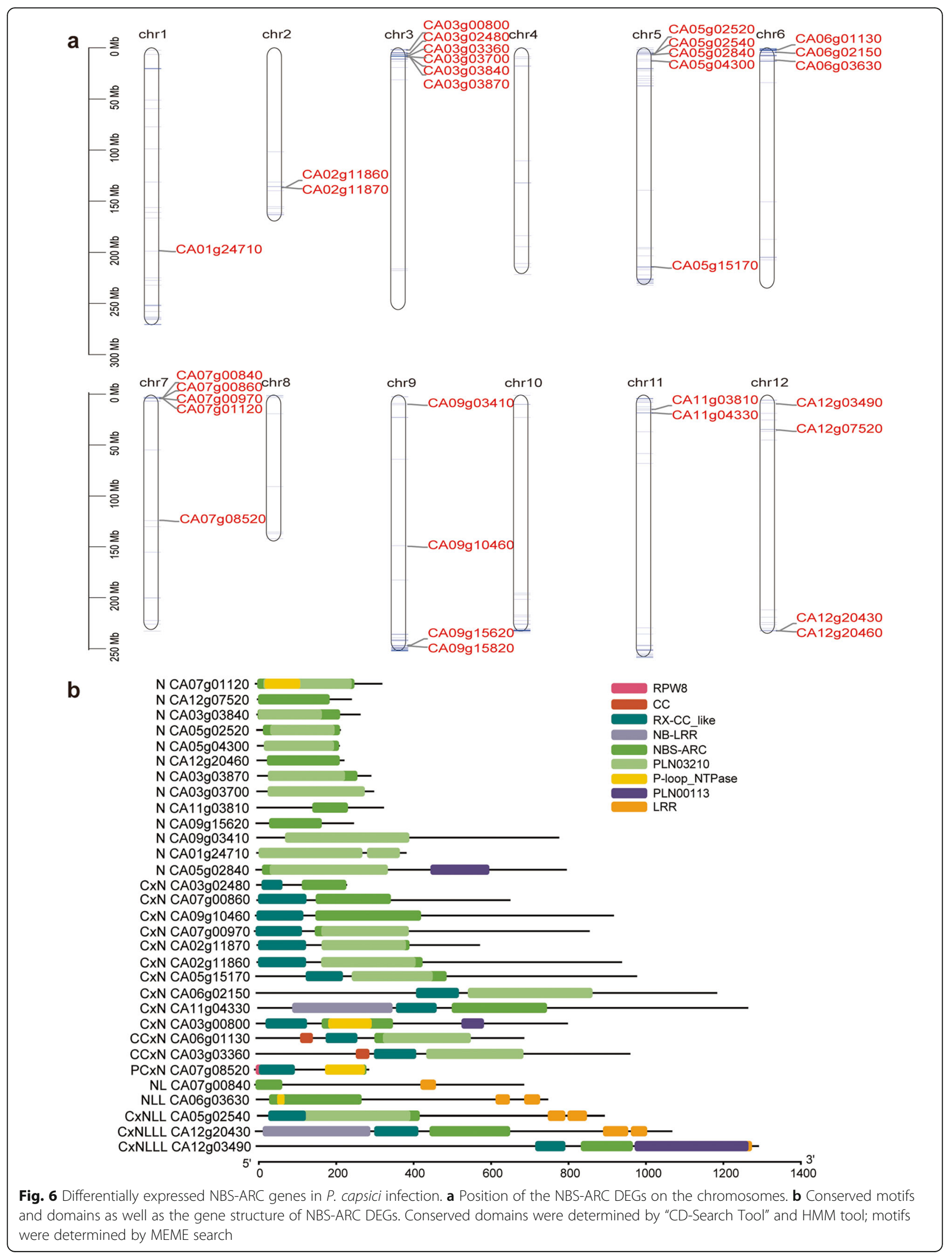




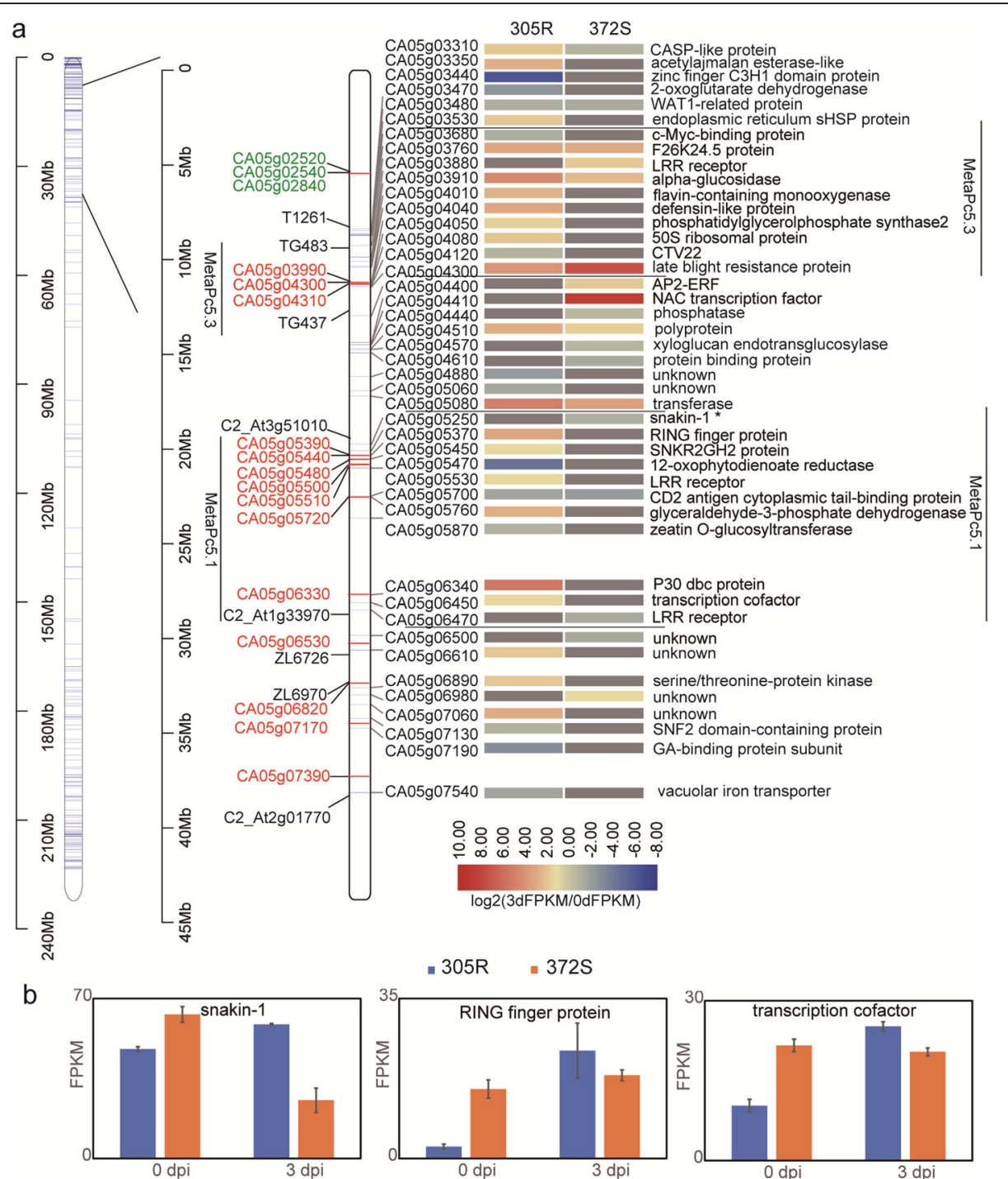

Fig. 7 Response profiles of genes positioned within Ext-Pc5.1 (between T1261 and C2_At2g01770). a All the NBS-ARC genes at Ext-Pc5.1 were labeled in red. All the DEGs at Ext-PC5.1 are shown on the right of the chromosome with a transcription heatmap and gene annotation. There were three NBS-ARC DEGs nearing Ext-PC5.1. b Three DEGs at Meta Pc5.1 showed different dynamic profile in P. capsici infection

proposed the late blight resistance genes CA05g05390, CA05g05440, and CA05g05720 [26]. All of these studies, together with the QTL on chromosome 10, led to a consensus about the role of the $R$ genes in $P$. capsici resistance. Nevertheless, we did not detect any differential expression of all the candidate genes proposed at Pc5.1. Three other $R$ genes (CA05g02520, CA05g02540, CA05g02840) at positions $5.47-6.74 \mathrm{Mb}$ and a cluster of LRR receptor-like genes (CA05G02270, CA05G02310, CA05G02340, CA05G02350) located at $4.5-4.7 \mathrm{Mb}$ showed significant response. However, they are too far from the consensus Meta-Pc5.1 and other published $P c 5.1$. Instead, they are likely located at a rare locus $C C_{-}$ Pc5.4 [23]. These differential expressions are probably $P$. capsici-specific because their expression was not affected by inoculation with Phytophthora infestans, pepper mottle virus, or tobacco mosaic virus [46]. Reverse genetic studies stress the function of many other factors in $P$. capsici resistance, e.g., CaRGA2 [47], EDS1 [11], CaChiIV1 [48], CaAP2/ERF064 [49], and squamosal promoter binding protein (SBP) [50]. However, no significant response of these genes was identified at the locus Pc5.1.

Snakin-1 (SN1) gene (CA05g05250) encoding a cysteine-rich antimicrobial peptide (AMP) might contribute to the broad-spectrum QTL. Snakin protein which was also called gibberellin stimulated peptide is firstly and thoroughly studied in potato since 1990s [51]. Many studies have proved that snakin proteins show strong antimicrobial activity in vivo and in vitro. Over 
expression of potato SN1 can increase resistance against fungal pathogens in wheat [52], alfalfa [53], and lettuce [54]. In pepper, CaSnakin protein was induced by rootknot nematode infection and play a role in resistance to nematode [55]. More genetic evidences need to be provided in the future to clarify it function in $P$. capsiciresistance.

\section{Conclusions}

We screened out 10 pepper materials showing high resistance to $P$. capsica. Primary metabolites of infected root were detected by GC-MS and sugars were greatly upregulated by $P$. capsica infection in 305R but not in 372S.We dissect the response of Ext-Pc5.1 and $R$ genes in $P$. capsici infection in transcriptome analysis. A total of 570 NBS-ARC genes were identified in pepper CM334 genome, among which 34 genes were affected by the infection, but only 5 genes belonged to NB-LRR type. These NB-LRR DEGs were not positioned at ExtPc5.1 and all the candidate genes proposed in previous publications did not show any response in $P$. capsici infection. These results provide new insights about the role of $R$ genes at the broad-spectrum Pc5.1 QTL. At least, we should not ascribe the $P$. capsici-resistance controlled by $P c 5.1$ to the transcriptional response of $R$ genes. We propose SN1 at Meta-Pc5.1 as the candidate gene controlling the wide-spectrum resistance. In addition, we found interesting and very clear response of sugar metabolism and processes of epigenetic modification systems, which provide a new insight into the resistance mechanism.

\section{Materials and methods Plant materials}

Phytophthora-resistant peppers were screened from 160 germplasm materials. All pepper seedlings were cultured in plug trays with 50 cells in a culture room. Ten seedlings for each accession were surveyed in the resistance investigation at the stage of 6 leaves. The known pepper CM334 with high resistance was used as a positive control. Two resistant accessions, 304R and 305R, and two susceptible accessions, $370 \mathrm{~S}$ and $372 \mathrm{~S}$, were identified and used in metabolite analysis and RNA-seq. Entire roots from each seedling were collected at $0 \mathrm{dpi}, 3$ $\mathrm{dpi}$, and $5 \mathrm{dpi}$ according to the development of the dynamic symptom. There was no symptom at $0 \mathrm{dpi}$; symptom appeared at $3 \mathrm{dpi}$; the whole plant became wilting at 5 dpi. Roots from 5 seedlings were mixed and homogenized as one sample. Triplicate samples were obtained at each sampling time point. All the samples were used to analyze the dynamic changes in root metabolites. The same samples at $0 \mathrm{dpi}$ and 3 dpi were also used in RNA-seq.

\section{$P$. capsici infection and resistance identification}

The $P$. capsici isolate named LJYM1 was provided by $\mathrm{Si}-$ chuan Academy of Agricultural Sciences, which were collected from Chengdu, China and was identified as physiological race 2 [56]. The inoculation method of disease PPR followed that described by Kimble [2]. Subcultures were performed on potato dextrose agar (PDA) medium at $27^{\circ} \mathrm{C}$ in the dark. Proliferation culture was performed on V8 medium in the dark until the plates were uniformly covered with mycelia. Zoospores were then induced in light and collected to make zoospore solutions with a concentration of $10^{5}$ spores $/ \mathrm{ml}$. Five milliliters of zoospore solution was injected into the soil around the basal stem of pepper seedlings at the 6-leaf stage. Injury of disease PPR was assessed from 0 to 10 dpi following the standard method described by $\mathrm{Li}$ et al. (2006) [57]. Resistance assessment was performed according to the index of disease injury at $5 \mathrm{dpi}$. High resistance (HR) was determined by very low disease index (0-10); Resistance (R) was determined by low disease index (10-25); moderate resistance (MR) was determined by moderate disease index (25-50); nonresistance (NR) was determined by high disease index (50-100).

\section{Metabolite extraction and GC-MS analysis}

The method of metabolite extraction and detection follows Desbrosses et al. (2005) with modification [58]. In brief, each root sample was dried by a vacuum freeze dryer at $-40^{\circ} \mathrm{C}$, and $100 \mathrm{mg}$ tissues were pulverized in a 2-ml tube using a slender glass pestle. Ground samples were suspended in $540 \mu \mathrm{l}$ precooled methanol plus $60 \mu \mathrm{l}$ ribitol in methanol $(2 \mathrm{mg} / \mathrm{ml})$, which was used as an internal standard. The tube was vortexed and then put in a water bath at $4{ }^{\circ} \mathrm{C}$ for $30 \mathrm{~min}$ with ultrasonic treatment. After adding $600 \mu \mathrm{l}$ of water and $300 \mu \mathrm{l}$ of chloroform, the samples were vortexed and then centrifuged at $14,000 \mathrm{rpm}$ for $10 \mathrm{~min}$ at room temperature. We then transferred $400 \mu \mathrm{l}$ aliquots of the aqueous phase to $2 \mathrm{ml}$ tubes and dried them at room temperature by vacuum centrifugation. The precipitate metabolites were suspended and derivatized by methoxyamination in $40 \mu \mathrm{l}$ methoxyamine hydrochloride in pyridine $(20 \mathrm{mg} / \mathrm{ml})$ for $2 \mathrm{~h}$ at $37^{\circ} \mathrm{C}$. Subsequent trimethylsilylation was performed at $37^{\circ} \mathrm{C}$ for $30 \mathrm{~min}$ after adding $70 \mu \mathrm{l}$ MSTFA solution. The derivatized solution was filtered through a $45-\mu \mathrm{m}$ membrane after adding $900 \mu \mathrm{l}$ hexane. All chemicals and reagents were of analytical grade.

Qualitative detection of primary metabolites in roots was performed using an Agilent GC-MS (7890A-5975C) equipped with an HP-5MS column $(30.0 \mathrm{~m} \times 0.25 \mathrm{~mm} \times$ $0.25 \mu \mathrm{m})$. One $\mu \mathrm{l}$ sample was injected in split-less mode. The oven temperature was initially maintained at $100^{\circ} \mathrm{C}$ for $1 \mathrm{~min}$, increased to $184{ }^{\circ} \mathrm{C}$ at a rate of $3{ }^{\circ} \mathrm{C} / \mathrm{min}$, increased to $190{ }^{\circ} \mathrm{C}$ at a rate of $0.5{ }^{\circ} \mathrm{C} / \mathrm{min}$, and finally 
increased to $280{ }^{\circ} \mathrm{C}$ at a rate of $15^{\circ} \mathrm{C} / \mathrm{min}$. Mass spectra were collected at a scanning range of $40-600 \mathrm{~m} / \mathrm{z}$. Each metabolite was identified by retention indices and comparison of mass spectra with a reference mass spectral library (NIST2011, Gaithersburg, MD, USA).

\section{RNA-seq and differential gene expression caused by $P$. capsici infection}

Root samples were ground into power in liquid nitrogen, and $100 \mathrm{mg}$ of each sample was used to extract total RNA using the TRIzol method as previously described [59]. One microgram of total RNA was purified via DNase I digestion. Poly(A) mRNAs were enriched using oligo (dT) magnetic particles. The obtained mRNA was fragmented via metal hydrolysis in $1 \times$ fragmentation buffer (Life Technologies) and then ligated to an RNA oligonucleotide adaptor. The ligation products were used to generate first-strand cDNA via reverse transcription (RT)-PCR. Then, short PCR was performed to amplify the cDNA to obtain sufficient quantities of DNA products. A single ' $A$ ' nucleotide was added to the 3 ' ends of cDNAs to facilitate ligation with adapters. Sequencing was performed using an Illumina Genome Analyzer IIx according to the manufacturer's instructions.

Reads with adapters, reads with greater than $10 \%$ unknown bases, and low-quality reads were filtered to obtain clean reads. Clean reads were mapped to the CM334 genome (ftp://ftp.solgenomics.net/genomes/ Capsicum_annuum/) using HISAT2 [60] and assembled the transcripts with mapped reads using StringTie [61]. For the analysis of protein-coding genes, only uniquely mapped reads were used, and the transcript levels were calculated as fragments per kilobase of transcript per million fragments (FPKM) using the Cufflinks software package [62]. DEGs were identified using DEseq [63], and the criteria were FDR $<0.01$ and fold-change $\geq 2$.

\section{Identification of NBS-ARC domain genes}

The genomic assembly and annotation of CM334 were downloaded from the Sol Genomics Network (ftp://ftp. solgenomics.net/genomes/Capsicum_annuum/). NBSARC candidate proteins were screened using HMMER v3 as described by Lozano et al. (2015) with minor alterations [43]. A hidden Markov model (HMM) of the NBS-ARC family (PF00931) from the Pfam database (http://pfam.sanger.ac.uk/) was used to search NBS-ARC domain proteins from genomic amino acid sequences using the function "hmmsearch" of HMMER v3. A pepper-specific NBS-ARC HMM was created from the obtained high-quality protein set $\left(E-v a l u e<1 \times 10^{-55}\right.$ ) using the function "hmmbuild" of HMMER v3. The obtained specific HMM file was used to search NBS-ARC domain proteins again from genomic amino acid sequences using the function "hmmsearch". Candidate proteins with an E-value $<0.01$ and lengths shorter than $200 \mathrm{bp}$ were discarded. The HMMs of NBC-ARC (PF00931), TIR (PF01582), RPW8 (PF05659), and LRR (PF00560, PF07723, PF07725, and PF12799) from the Pfam database were merged into one HMM by the function "hmmpress" and used to mine the corresponding domains by the "hmmscan" HMMER v3 suite. Paircoliled 2 (http://cb.csail.mit.edu/cb/paircoil2/paircoil2. html) was used to identify the CC domain with a Pscore cutoff of 0.03 and minimum search window length of 21. Conserved domains were confirmed by the Batch Web CD-Search Tool (https://www.ncbi.nlm.nih.gov/ Structure/bwrpsb/bwrpsb.cgi) and Multiple Expectation for Motif Elicitation (MEME). All the identified NBSARC domain proteins were grouped according to the number and position of NBS-ARC, CC, TIR, RPW8, LRR, and RX-CC_like. Tree topology of NBS-ARC genes was constructed by MEGA7 [64]. The visualization of gene structure and domain pattern was done by using TBTools [65].

\section{Abbreviations}

DPI: Days post inoculation; DEG: Differentially expressed gene; KEGG: Kyoto encyclopedia of genes and genomes; GO: Gene ontology; PRR: Phytophthora capsici root rot; QTL: Quantitative Trait Locus; PTI: Pattern-triggered immunity; ETI: Effector-triggered immunity; NBS: Nucleotide binding site; ARC: Apoptosis, R proteins, CED-4; LRR: Leucine rich repeat; TIR: Toll/ interleukin-1 receptor; RPW8: Resistance to powdery mildew 8; CC: Coiledcoil; RX-CC: Coiled coil domain of the potato virus $X$ resistance; $C x$ : $R X-C C$; HR: High resistance; MR: Moderate resistance; NR: Nonresistance; RPP13: Resistance to Peronospora parasitica protein 13; SN1: Snakin-1; PR: Pathogenesis-related

\section{Supplementary Information}

The online version contains supplementary material available at https://doi. org/10.1186/s12864-021-07705-z.

Additional file 1: Table S1. Assessment of resistance against $P$. capsici in peppers.

Additional file 2: Table S2. Raw data of RNA-sequencing.

Additional file 3: Table S3. DEGs identified in 305R root transcriptome after $P$. capsici inoculation.

Additional file 4: Table S4. DEGs identified in 3725 root transcriptome after $P$. capsici inoculation.

Additional file 5: Table S5. DEGs that were enriched in Epigeneticrelated biological processes in $\mathrm{GO}$ enrichment analysis.

Additional file 6: Table S6. Detailed information of each NBS-ARC protein on the representative conserved domains.

Additional file 7: Table S7. Classification of NBS-ARC domain proteins in peppers.

Additional file 8: Figure S1. Top 20 enrichments in KEEG enrichment analysis.

Additional file 9: Figure S2. GO enrichment analysis of DEGs. Additional file 10: Figure S3. Transcription heatmap of genes of phenylpropanoid pathway in KEGG analysis.

Additional file 11: Figure S4. The dynamic change of sugar pathway genes after $P$. capsici infection in 3725 .

Additional file 12: Figure S5. Position of NBS-ARC domain genes on pepper chromosomes. 
Additional file 13. Protein structure and gene structure of NBS-ARC genes with complete NBS-ARC domains.

\section{Acknowledgments}

Part of the Capsicum germplasm was kindly provided by Prof. Xixiang Li from The Lab of Vegetable Germplasm, Institute of Flowers and Vegetable, Chinese Academy of Agricultural Science. The P. capsici isolate was kindly provided by Dr. Yadong Xi from Sichuan Academy of Agricultural Sciences.

\section{Authors' contributions}

JSD and LFH did the resistance assessment. YSL designed the experiment and organized the manuscript. XYX, RSEB, and LHS prepared the sample for sequencing. QH, HTY, SA, and HQT did the transcriptome analysis. KXZ and $Y L$ performed the root metabolites detection. $H X L, B S$, and $L J$ contributed the manuscript revision. The authors have carefully read and approved the final manuscript.

\section{Funding}

This work was supported by the Science \& Technology Department of Sichuan Province (2018HH0124).

\section{Availability of data and materials}

The clean data of RNA-seq were deposited in the NCBI GeneBank under accession number SAMN17915256, SAMN17915257, SAMN17915258, SAMN17915259.

\section{Declarations}

\section{Ethics approval and consent to participate}

Among the capsicum germplasm used in this study, 100 accessions were introduced from the Lab of Vegetable Germplasm, Institute of Flowers and Vegetable, Chinese Academy of Agricultural Science, and 60 accessions were preserved by Sichuan Agricultural University. All the accessions were selfpollinated by the authors for at least 5 generations. These plant materials don't include any wild species at risk of extinction. No specific permits are required for sample collection in this study. We comply with relevant institutional, national, and international guidelines and legislation for plant study.

\section{Consent for publication}

Not applicable.

\section{Competing interests}

The authors declare that they have no competing interests.

Received: 10 February 2021 Accepted: 6 May 2021

Published online: 21 May 2021

\section{References}

1. Black LL, Green SK, Hartman GL, Poulos JM. Pepper diseases: a field guide Taipei: Asian vegetable Researh and development center; 1991.

2. Kimble KA, Grogan RG. Resistance to Phytophthora root rot in pepper. Plant Dis Rep. 1960;44:872-3.

3. Guerrero-Moreno A, Laborde JA. Current status of pepper breeding for resistance to Phytophthora capsici in Mexico In: Synopses IVth Meeting Eucarpia Capsicum working group, 14-16 Otober 1980 Wageningen, Holland; 1980. p. 52-6.

4. Leonian LH. Stem and fruit blight of peppers caused by Phytophthora capsici sp.nov. Phytopathology. 1922;12:401-8.

5. Hausbeck MK, Lamour KH. Phytophthora capsici on vegetable crops: research progress and management challenges. Plant Dis. 2004;12:1292303.

6. Lamour $\mathrm{KH}$, Stam R, Jupe J, Huitema E. The oomycete broad-host-range pathogen Phytophthora capsici. Mol Plant Pathol. 2012;14:329-37.

7. Wang Y, Bouwmeester K, van de Mortel JE, Shan W, Govers F. A novel Arabidopsis-oomycete pathosystem: differential inter-actions with Phytophthora capsici reveal a role for camalexin, indole glucosinolates and salicylic acid in defence. Plant Cell Environ. 2013;36(6):1192-203. https://doi. org/10.1111/pce.12052.
8. Ortega GR, Espanol CP, Zueco JC. Interaction in the pepper-Phytophthora capsici system. Plant Breed. 1995;114(1):74-7. https://doi.org/10.1111/j.14390523.1995.tb00763.x

9. He Q, McLellan H, Hughes RK, Boevink PC, Armstrong M, Lu Y, et al. Phytophthora infestans effector SFI3 targets potato UBK to suppress early immune transcriptional responses. New Phytol. 2019;222(1):438-54. https:// doi.org/10.1111/nph.15635.

10. Fan G, Yang Y, Li T, Lu W, Du Y, Qiang X, et al. A Phytophthora capsici RXLR effector targets and inhibits a plant PPlase to suppress endoplasmic reticulum-mediated immunity. Mol Plant. 2018;11(8):1067-83. https://doi. org/10.1016/j.molp.2018.05.009.

11. Li Q, Wang J, Bai T, Zhang M, Jia Y, Shen D, et al. A Phytophthora capsici effector suppresses plant immunity via interaction with EDS1. Mol Plant Pathol. 2020;21(4):502-11. https://doi.org/10.1111/mpp.12912.

12. Li H, Wang $H$, Jing $M$, Zhu J, Guo B, Wang Y, et al. A Phytophthora effector recruits a host cytoplasmic transacetylase into nuclear speckles to enhance plant susceptibility. eLife. 2018;7:e40039. https://doi.org/10.7554/eLife.40039.

13. Yang B, Wang Y, Guo B, Jing M, Zhou H, Li Y, et al. The Phytophthora sojae RXLR effector Avh238 destabilizes soybean Type2 GmACSs to suppress ethylene biosynthesis and promote infection. New Phytol. 2019;222(1):42537. https://doi.org/10.1111/nph.15581.

14. Jones JDG, Dangl JL. The plant immune system. Nature. 2006;444(7117): 323-9. https://doi.org/10.1038/nature05286.

15. Wan H, Yuan W, Ye Q, Wang R, Ruan M, Li Z, et al. Analysis of TIR- and nonTIR-NBS-LRR disease resistance gene analogous in pepper: characterization, genetic variation, functional divergence and expression patterns. BMC Genomics. 2012;13(1):502. https://doi.org/10.1186/1471-2164-13-502.

16. Naresh P, Reddy MK, Reddy AC, Lavanya B, Reddy DCL, Reddy KM. Isolation, characterization and genetic diversity of NBS-LRR class disease-resistant gene analogs in multiple virus resistant line of chilli (Capsicum annuum L.) Biotech. 2017;7:114.

17. Lozano R, Ponce O, Ramirez M, Mostajo N, Orjeda G. Genome-wide identification and mapping of NBS-encoding resistance genes in Solanum tuberosum group phureja. PLoS One. 2012;7(4):e34775. https://doi.org/10.13 71/journal.pone.0034775.

18. Lefebvre $\vee$, Palloix A. Both epistatic and additive effects of QTLs are involved in polygenic induced resistance to disease: a case study, the interaction pepper - Phytophthora capsici Leonian. Theor Appl Genet. 1996; 93(4):503-11. https://doi.org/10.1007/BF00417941.

19. Thabuis A, Palloix A, Pflieger S, Daubeze AM, Caranta C, Lefebvre V. Comparative mapping of Phytophthora resistance loci in pepper germplasm: evidence for conserved resistance loci across Solanaceae and for a large genetic diversity. Theor Appl Genet. 2003;106(8):1473-85. https://doi.org/1 0.1007/s00122-003-1206-3.

20. Ogundiwin EA, Berke TF, Massoudi M, Black LL, Huestis G, Choi D, et al. Construction of 2 intraspecific linkage maps and identification of resistance QTLs for Phytophthora capsici root-rot and foliar-blight diseases of pepper (Capsicum annuum L.). Genome. 2005;48(4):698-711. https://doi.org/10.1139/ g05-028.

21. Yi TY, Xie BY, Zhang B, Yang YH, Gao BD. Inheritance of resistance traits related to Phytophthora capsici in Capsicum annuum and analysis of relative AFLP markers. J Agric Biotech. 2007;15:847-54

22. Bonnet J, Danan S, Boudet C, Barchi L, Sage-Palloix AM, Caromel B, et al. Are the polygenic architectures of resistance to Phytophthora capsici and $P$. parasitica independent in pepper? Theor Appl Genet. 2007;115(2):253-64. https://doi.org/10.1007/s00122-007-0561-x.

23. Kim HJ, Nahm SH, Lee HR, Yoon GB, Kim KT, Kang BC, et al. BAC-derived markers converted from RFLP linked to Phytophthora capsici resistance in pepper (Capsicum annuum L.). Theor Appl Genet. 2008;118:15-27.

24. Mallard S, Cantet M, Massire A, Bachellez A, Ewert S, Lefebvre V. A key QTL cluster is conserved among accessions and exhibits broadspectrum resistance to Phytophthora capsici: a valuable locus for pepper breeding. Mol Breed. 2013;32(2):349-64. https://doi.org/10.1007/s11032013-9875-3.

25. Wang P, Wang L, Guo J, Yang W, Shen H. Molecular mapping of a gene conferring resistance to Phytophthora capsici Leonian race 2 in pepper line PI201234 (Capsicum annuum L.). Mol Breeding. 2016;36:66.

26. Chunthawodtiporn J, Hill T, Stoffel K, Deynze AV. Genetic analysis of resistance to multiple isolates of Phytophthora capsici and linkage to horticultural traits in bell pepper. HortScience. 2019;54(7):1143-8. https://doi. org/10.21273/HORTSCI13359-18. 
27. Siddique MI, Lee HY, Ro NY, Han K, Venkatesh J, Solomon AM, et al. Identifying candidate genes for Phytophthora capsici resistance in pepper (Capsicum annuum) via genotyping-by-sequencing-based QTL mapping and genome-wide association study. Sci Rep. 2019;9(1):9962. https://doi. org/10.1038/s41598-019-46342-1.

28. Kim S, Park M, Yeom SI, Kim YM, Lee JM, Lee HA, et al. Genome sequence of the hot pepper provides insights into the evolution of pungency in Capsicum species. Nat Genet. 2014;46(3):270-8. https://doi.org/10.1038/ng.2877.

29. Qin C, Yu C, Shen Y, Fang X, Chen L, Min J, et al. Whole-genome sequencing of cultivated and wild peppers provides insights into Capsicum domestication and specialization. Proc Natl Acad Sci U S A. 2014;111(14): 5135-40. https://doi.org/10.1073/pnas.1400975111.

30. Liu Y, Teng C, Xia R, Meyers BC. PhasiRNAs in plants: their biogenesis, genic sources, and roles in stress responses, development, and reproduction. Plant Cell. 2020;32(10):3059-80. https://doi.org/10.1105/tpc.20.00335.

31. Almasia NI, Nahirñak V, Hopp HE, Vazquez-Rovere C. Potato Snakin-1: an antimicrobial player of the trade-of between host defense and development. Plant Cell Rep. 2020;39(7):839-49. https://doi.org/10.1007/s002 99-020-02557-5.

32. Wang P, Wu H, Zhao G, He Y, Kong W, Zhang J, et al. Transcriptome analysis clarified genes involved in resistance to Phytophthora capsici in melon. PLOS One. 2020;15(2):e0227284. https://doi.org/10.1371/journal.pone.0227284.

33. Ranjan A, Westrick NM, Jain S, Piotrowski JS, Ranjan M, Kessens R, et al. Resistance against Sclerotinia sclerotiorum in soybean involves a reprogramming of the phenylpropanoid pathway and up-regulation of antifungal activity targeting ergosterol biosynthesis. Plant Biotechnol J. 2019;17(8):1567-81. https://doi.org/10.1111/pbi.13082.

34. Binder S. Branched-chain amino acid metabolism in Arabidopsis thaliana. Arabidopsis Book. 2010;8:e0137. https://doi.org/10.1199/tab.0137.

35. Tirnaz S, Batley J. DNA methylation: toward crop disease resistance improvement. Trends Plant Sci. 2019;24(12):1137-50. https://doi.org/10.1016/ j.tplants.2019.08.007.

36. Roberts MR, López A. Plant epigenetic mechanisms in response to biotic stress. In: Alvarez-Venegas R, De-la-Peña C, Casas-Mollano J, editors. Epigenetics in plants of agronomic importance: fundamentals and applications. Cham: Springer, Cham; 2019. p. 65-113.

37. Cai Q, Liang C, Wang S, Hou Y, Gao L, Liu L, et al. The disease resistance protein SNC1 represses the biogenesis of microRNAs and phased siRNAs. Nat Commun. 2018;9(1):5080. https://doi.org/10.1038/s41467-018-07516-z.

38. Morkunas I, Ratajczak $L$. The role of sugar signaling in plant defense responses against fungal pathogens. Acta Physiol Plant. 2014;36(7):1607-19. https://doi.org/10.1007/s11738-014-1559-z.

39. Bolouri Moghaddam MR, Van den Ende W. Sugars and plant innate immunity. J Exp Bot. 2012;63(11):3989-98. https://doi.org/10.1093/jxb/ers129.

40. Roitsch T, Balibrea ME, Hofmann M, Proels R, Sinha AK. Extracellular invertase: key metabolic enzyme and PR protein. J Exp Bot. 2003;54(382): 513-24. https://doi.org/10.1093/jxb/erg050.

41. Gómez-Ariza J, Campo S, Rufat M, Estopà M, Messeguer J, San Segundo B, et al. Sucrose-mediated priming of plant defense responses and broadspectrum disease resistance by overexpression of the maize pathogenesisrelated PRms protein in rice plants. Mol Plant-Microbe Interact. 2007;20(7): 832-42. https://doi.org/10.1094/MPMI-20-7-0832.

42. Meng D, Li C, Park HJ, González J, Wang J, Dandekar AM, et al. Sorbitol modulates resistance to alternaria alternata by regulating the expression of an NLR resistance gene in apple. Plant Cell. 2018;30(7):1562-81. https://doi. org/10.1105/tpc.18.00231.

43. Lozano R, Hamblin MT, Prochnik S, Jannink J. Identification and distribution of the NBS-LRR gene family in the cassava genome. BMC Genomics. 2015;7: 360.

44. Collier SM, Moffett P. NB-LRRs work a "bait and switch" on pathogens. Trends Plant Sci. 2009;14(10):521-9. https://doi.org/10.1016/j.tplants.2009.08. 001.

45. Xu X, Chao J, Cheng X, Wang R, Wang H, Luo S, et al. Mapping of a novel race specific resistance gene to Phytophthora root rot of pepper (Capsicum annuum) using bulked segregant analysis combined with specific length amplified fragment sequencing strategy. PLoS One. 2016;11(3):e0151401. https://doi.org/10.1371/journal.pone.0151401.

46. Kim MS, Kim S, Jeon J, Kim KT, Lee HA, Lee HY, et al. Global gene expression profiling for fruit organs and pathogen infections in the pepper, Capsicum annuum L. Sci Data. 2018:5(1):180103. https://doi.org/10.1038/sda ta.2018.103.
47. Zhang YL, Jia QL, Li DW, Wang JE, Yin YX, Gong ZH. Characteristic of the pepper CaRGA2 gene in defense responses against Phytophthora capsici Leonian. Int J Mol Sci. 2013;14(5):8985-9004. https://doi.org/10.3390/ijms14 058985.

48. Ali M, Gai WX, Khattak AM, Khan A, Haq SU, Ma X, et al. Knockdown of the chitin-binding protein family gene CaChilV1 increased sensitivity to Phytophthora capsici and drought stress in pepper plants. Mol Gen Genomics. 2019;294(5):1311-26. https://doi.org/10.1007/s00438-019-01583-7.

49. Jin JH, Zhang HX, Ali M, Wei AM, LD X, Gong ZH. The CaAP2/ERF064 regulates dual functions in pepper: plant cell death and resistance to Phytophthora capsici. Genes. 2019;10:541.

50. Zhang $H X$, Feng $X H$, Ali M, Jin JH, Wei AM, Khattak AM, et al. Identification of pepper CaSBP08 gene in defense response against Phytophthora capsici infection. Front Plant Sci. 2020;11:183. https://doi.org/10.3389/fpls.2020.001 83.

51. Segura A, Moreno M, Madueño F, Molina A, García-Olmedo F. Snakin-1, a peptide from potato that is active against plant pathogens. Mol PlantMicrobe Interact. 1999;12(1):16-23. https://doi.org/10.1094/MPMI.1999.12.1.1 6.

52. Rong W, Qi L, Wang J, Du L, Xu H, Wang A, et al. Expression of a potato antimicrobial peptide SN1 increases resistance to take-all pathogen Gaeumannomyces graminis var. tritici in transgenic wheat. Funct Integr Genomics. 2013;13(3):403-9. https://doi.org/10.1007/s10142-013-0332-5.

53. García AN, Ayub ND, Fox AR, Gómez MC, Diéguez MJ, Pagano EMB, et al. Alfalfa Snakin-1 prevents fungal colonization and probably coevolved with rhizobia. BMC Plant Biol. 2014;14:1-13.

54. Darqui FS, Radonic LM, Trotz PM, López N, Vázquez Rovere C, Hopp HE, et al. Potato Snakin-1 gene enhances tolerance to Rhizoctonia solani and Sclerotinia sclerotiorum in transgenic lettuce plants. J Biotechnol. 2018;283: 62-9. https://doi.org/10.1016/j.jbiotec.2018.07.017.

55. Mao Z, Zheng J, Wang Y, Chen G, Yang Y, Feng D, et al. The new CaSn gene belonging to the Snakin family induces resistance against root-knot nematode infection in pepper. Phytoparasitica. 2011;39(2):151-64. https:// doi.org/10.1007/s12600-011-0149-5.

56. Han S, Zhang HQ, Wu J, Li HH, Xi YD. Identification and evaluation of capsicum varieties resistance to Phytophthora capsica in Sichuan Province. China Vegetables. 2019;7:56-61 (in Chinese).

57. Li X, Zhang B. Descriptor and data standard for Capsicum (Capsicum annum L., Capsicum frutescens L., Capsicum chinense, Capsicum baccatum, Capsicum pubescens). Beijing: China Agriculture Press; 2006. (in Chinese)

58. Desbrosses G, Steinhauser D, Kopka J, Udvardi M. Metabolome analysis using GC-MS. In: Márquez AJ, editor. Lotus japonicus handbook. Dordrecht: Springer, Dordrecht; 2005. p. 165-74.

59. Feinbaum $\mathrm{RL}$, Ausubel FM. Transcriptional regulation of the Arabidopsis thaliana chalcone synthase gene. Mol Cell Biol. 1988;8(5):1985-92. https:// doi.org/10.1128/MCB.8.5.1985.

60. Kim D, Langmead B, Salzberg SL. HISAT: a fast spliced aligner with low memory requirements. Nat Methods. 2015;12(4):357-60. https://doi.org/10.1 038/nmeth.3317.

61. Pertea M, Pertea GM, Antonescu CM, Chang T, Mendell JT, Salzberg SL. StringTie enables improved reconstruction of a transcriptome from RNA-seq reads. Nat Biotechnol. 2015;33(3):290-5. https://doi.org/10.1038/nbt.3122.

62. Mortazavi A, Williams BA, McCue K, Schaeffer L, Wold B. Mapping and quantifying mammalian transcriptomes by RNA-Seq. Nat Methods. 2008;5(7): 621-8. https://doi.org/10.1038/nmeth.1226.

63. Wang L, Feng Z, Wang X, Zhang X. DEGseq: an R package for identifying differentially expressed genes from RNA-seq data. Bioinformatics. 2010;26(1): 136-8. https://doi.org/10.1093/bioinformatics/btp612.

64. Kumar S, Stecher G, Tamura K. MEGA7: molecular evolutionary genetics analysis version 7.0 for bigger datasets. Mol Biol Evol. 2016;33(7):1870-4. https://doi.org/10.1093/molbev/msw054.

65. Chen C, Chen H, Zhang Y, Thomas HR, Frank MH, He Y, et al. TBtools: an integrative toolkit developed for interactive analyses of big biological data. Mol Plant. 2020;13(8):1194-202. https://doi.org/10.1016/j.molp.2020.06.009.

\section{Publisher's Note}

Springer Nature remains neutral with regard to jurisdictional claims in published maps and institutional affiliations. 